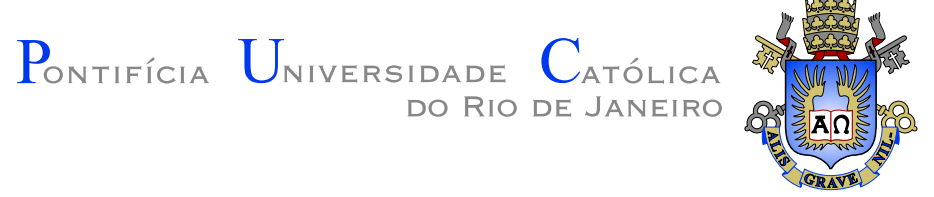

Bárbara Lúcia de Almeida

\title{
Síntese e caracterização de compostos com poliaminas, adenosina 5'trifosfato, fosfocreatina e alguns metais de interesse biológico
}

Tese apresentada ao Programa de Pós-graduação em Química do Departamento de Química da PUC-Rio como requisito parcial para obtenção do título de Doutor em Química

Orientador: Prof. Judith Felcman 


\title{
Bárbara Lúcia de Almeida
}

\section{Síntese e caracterização de compostos com poliaminas, adenosina 5'trifosfato, fosfocreatina e alguns metais de interesse \\ biológico}

Tese apresentada ao Programa de Pós-graduação em Química do Departamento de Química do Centro Técnico Científico da PUCRio como requisito parcial para obtenção Do título de Doutor em Química. Aprovada pela Comissão Examinadora abaixo assinada.

\author{
Prof. Judith Felcman \\ Orientador \\ Departamento de Química - PUC-Rio \\ Prof. Letícia Regina de Souza Teixeira \\ PUC-Rio
}

Prof. Joana Mara Teixeira

UERJ

Prof. Ana Paula Soares Fontes

UFJF

Prof. Claudio Alberto Tellez Soto

UFF

Prof. Otavio Versiane Cabral

CEFETEQ

Prof. José Eugenio Leal

Coordenador Setorial do Centro Técnico Científico - PUC-Rio 
Todos os direitos reservados. É proibida a reprodução total ou parcial do trabalho sem autorização da universidade, do autor e do orientador.

\section{Bárbara Lúcia de Almeida}

Graduou-se em Química, bacharelado e licenciatura, na Universidade Federal de Juiz de Fora. Durante o mestrado foi bolsista CAPES, desenvolvendo trabalho em química bioinorgânica, na Universidade Federal de Juiz de Fora.

Ficha Catalográfica

Almeida, Bárbara L.

Síntese e caracterização de compostos com poliaminas, adenosina 5'trifosfato, fosfocreatina e alguns metais de interesse biológico / Bárbara Lúcia de Almeida; orientadora: Judith Felcman. - 2008.

219 f.: il.; $30 \mathrm{~cm}$

Tese (Doutorado em Química) - Pontifícia Universidade Católica do Rio de Janeiro, Rio de Janeiro, 2008.

Inclui bibliografia

1. Química - Teses. 2. Poliaminas biológicas. 3. Adenosina 5'Trifosfato. 4. Fosfocreatina. 5. Cobre(II). 6. Cobalto(II). 7. Cádmio(II). I. Felcman, Judith. II. Pontifícia Universidade Católica do Rio de Janeiro. Departamento de Química. III. Título. 


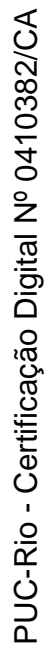

À Deus que me permitiu realizar mais um sonho. 


\section{Agradecimentos}

Agradeço à Dra . Judith Felcman pela oportunidade, orientação e amizade durante a realização deste trabalho.

Ao Dr. Otavio Versiane por toda ajuda e pelo tempo dispensado para nossas longas conversas durante boa parte do desenvolvimento deste trabalho.

Aos funcionários: o técnico Jorge, pela ajuda em todos os espectros, à secretária da pós-graduação Fátima, por sua eficiência e atenção, e ao Noberto, pelas informações que são sempre de grande ajuda.

A todos os colegas do laboratório: Marta, Luciana, Joanna, Pedro, Grisset, Fernanda, Vanessa, Débora, Natalie, Mônica, Cristiane e todos os outros, pelo companheirismo e pela amizade que deixa saudades. Em especial ao amigos José Arthur e Jacqueline pelas proveitosas discussões a respeito das poliaminas biológicas.

Ao Prof. Claudio Tellez da Universidade Federal Fluminense e à amiga Joanna, pela grande contribuição no trabalho com os cálculos teóricos dos compostos.

Ao Prof. Dr. Mangrich e a Drª . Ana Lúcia Mercê da Universidade Federal do Paraná, pelas análises de EPR.

À Dra . Erika, à FIOCRUZ e ao IME pelos espectros de RMN.

Ao Dr. Ernesto Lang e seu aluno Davi Fernando Back da Universidade Federal de Santa Maria, pela contribuição fundamental com a cristalografia.

Ao Departamento de Química da PUC-Rio pela oportunidade de realizar o trabalho de pós-graduação.

Ao Alexandre, pelo amor, carinho, companheirismo e pela força, que foi fundamental nos momentos em que a situação nos faz pensar em desistir.

À minha mãe Teresa, ao meu pai Jesus e minha irmã Jaqueline, que apesar da distância, estão sempre presentes e me dão incentivos e apoio para que eu realize todos os meus sonhos.

Aos pais do Alexandre, Edy e Roberto, pelo constante apoio em vários momentos de grandes necessidades.

Ao $\mathrm{CNPq}$ pelo apoio financeiro através da bolsa de doutorado.

A todas as pessoas, que de uma forma direta ou indireta, auxiliaram no desenvolvimento deste trabalho: o meu muito obrigada e minhas sinceras desculpas por ter esquecido o seu nome! 


\section{Resumo}

Almeida, Bárbara L.; Felcman, Judith. Síntese e caracterização de compostos com poliaminas, adenosina 5'trifosfato, fosfocreatina e alguns metais de interesse biológico. Rio de Janeiro, 2008. 219p. Tese de Doutorado - Departamento de Química, Pontifícia Universidade Católica do Rio de Janeiro.

Este trabalho descreve a síntese e caracterização de compostos de $\mathrm{Cu}(\mathrm{II}), \mathrm{Co}(\mathrm{II})$ e $\mathrm{Cd}(\mathrm{II})$. As técnicas de caracterização utilizadas foram análise elementar, termogravimetria, UV-vis, espectroscopia de infravermelho, RMN (para complexos de Cd(II)), EPR (para complexos de cobre (II)) e difração de raio $\mathrm{X}$, quando obtidos cristais. A primeira parte do trabalho foi a síntese de um novo complexo: $\left[\mathrm{Cu}(\mathrm{PCr})\left(\mathrm{H}_{2} \mathrm{O}\right)\right]$, e os resultados sugerem que a $\mathrm{PCr}$ age como um ligante tridentado (o átomo de nitrogênio do grupo guanidino e os átomos de oxigênio dos grupos fosfato e carboxilato como sendo os átomos doadores). A quarta posição na esfera de coordenação é ocupada por uma molécula de água. Estes resultados foram confirmados através de cálculos computacionais (DFT/B3LYP:6-311G procedimento teórico) e mostram que o cobre(II) está tetracoordenado com uma geometria quadrática plana. A segunda parte deste trabalho foi a síntese de quatro novos complexos do tipo $[\mathrm{Cu}(\mathrm{ATP})$ (poliamina)], contendo como ligante as poliaminas (PA): etilenodiamina, 1,3-diaminopropano, espermidina, espermina e o ATP. Os valores dos parâmetros paralelos de EPR para os complexos mostram que o íon cobre(II) está complexado através dos oxigênios dos fosfatos do ATP. Os dados da TG indicam que nos complexos estão presentes moléculas de água de hidratação. A parte final deste trabalho foi o estudo das interações dos sistemas entre as poliaminas e os tetraclorometalatos. Quatorze novos compostos de $\mathrm{Cu}$ (II), Co(II) e Cd(II) de estequiometria $\left[\mathrm{MCl}_{4}(\right.$ poliamina $\left.)\right]$ contendo, além das poliaminas já citadas, a poliamina putrescina foram preparados. Um complexo de $\mathrm{Co}$ (II) com a estequiometria $\left[\mathrm{CoCl}_{2}\left(\mathrm{H}_{2} \mathrm{O}\right)_{4}\right] \mathrm{Put} .2 \mathrm{HCl}$, foi preparado e formou cristais.

\section{Palavras-chave}

Poliaminas biológicas; Adenosina 5'Trifosfato; Fosfocreatina; Cobre(II); Cobalto(II); Cádmio(II). 


\section{Abstract}

Almeida, Bárbara L.; Felcman, Judith. Synthesis and Characterization of Polyamines, Adenosine 5'triphosphate, Phosphocreatine Compounds and Some Biological Interest Metals. Rio de Janeiro, 2008. 219p. PhD Thesis - Department of Química, Pontifícia Universidade Católica do Rio de Janeiro.

This work describes the synthesis and characterization of $\mathrm{Cu}(\mathrm{II})$, $\mathrm{Co}(\mathrm{II})$ e $\mathrm{Cd}(\mathrm{II})$ compounds. The characterization was performed by means of elemental and thermogravimetric analysis, UV-vis, IR, RMN (for $\mathrm{Cd}(\mathrm{II})$ compounds), EPR (for $\mathrm{Cu}(\mathrm{II})$ compounds) and X-ray diffractometry (for crystals). The first part of this work was the synthesis of one new complex : $\left[\mathrm{Cu}(\mathrm{PCr})\left(\mathrm{H}_{2} \mathrm{O}\right)\right]$ and the results suggest that $\mathrm{PCr}$ is acting as a tridentate ligand (the nitrogen atom of the guanidine group and the oxygen atom of the phosphate group and the carboxylate group being the donor atoms). The fourth position is occupied by a water molecule. These results were confirmed through computational calculations (DFT/B3LYP:6-311G theoretical procedure) and show that $\mathrm{Cu}(\mathrm{II})$ is tetracoordinated and arranged in a tetrahedric geometry. The second part of the study was the synthesis and characterization of four new complexes of the type $[\mathrm{Cu}(\mathrm{ATP})$ (polyamine)] containing as ligands the polyamines (PA): ethylenediamine, 1,3-diaminepropane, spermidine or spermine and ATP. The EPR parallel parameters values for the complexes show that $\mathrm{Cu}(\mathrm{II})$ is complexed through the oxygen atoms from the phosphates groups of ATP. TG data indicate that each complex has the presence of one water molecule of hydration. The final part of this work was the study of the interactions occurring in systems between tetrachlorometalates and the polyamines. Fourteen new compounds of $\mathrm{Cu}(\mathrm{II}), \mathrm{Co}(\mathrm{II})$ and $\mathrm{Cd}(\mathrm{II})$ of stoichiometry $\left[\mathrm{MCl}_{4}\right.$ (polyamine)] were prepared, containing all the polyamines cited before plus putrescine were prepared. One complex of $\mathrm{Co}$ (II) with the stoichiometry $\left[\mathrm{CoCl}_{2}\left(\mathrm{H}_{2} \mathrm{O}\right)_{4}\right] \mathrm{Put} .2 \mathrm{HCl}$, has formed single crystals.

\section{Keywords}

Biologic Polyamines; ATP; Phosphocreatine; Copper(II); Cobalt(II); Cadmium(II). 


\section{Sumário}

1 Introdução $\quad 17$

2 Ligantes $\quad 19$

2.1 Ligantes Aminados: Poliaminas 19

$\begin{array}{ll}2.1 .1 & 19 \\ & \text { Introdução }\end{array}$

2.1.2 Aspectos biológicos 20

2.1.3 Interações Intermoleculares: Características Estruturais 24

2.1.4 Interações com íons metálicos: sistemas ternários 27

2.1.5 Interações com íons metálicos: sistemas binários 29

2.2 Ligantes Fosfatados: Adenosina 5' trifosfato (ATP) 33

2.3 Ligantes Fosfatados: Fosfocreatina (PCr) 37

3 Metais $\quad 40$

3.1 Cobre(II) 40

3.1.1 Tetraclorocuprato (II) 44

3.2 Cobalto 45

3.2.1 Tetraclorocobaltato (II) 48

3.3 Cádmio(II) 49

3.3.1 Tetraclorocadmato(II) $\quad 51$

$4 \quad$ Parte Experimental $\quad 53$

4.1 Materiais e Métodos $\quad 53$

4.1.1 Lista de reagentes e solventes $\quad 53$

$\begin{array}{ll}4.1 .2 & \text { Equipamentos } \\ & 54\end{array}$

4.2 Ligantes $\quad 56$

4.2.1 Nomes oficiais $\quad 56$

4.2.2 Dados Experimentais do ATP e da PCr 56

4.2.2.1 Estruturas dos ligantes fosfatados $\quad 56$

$\begin{array}{ll}\text { 4.2.3 Dados Experimentais das Poliaminas } & 57\end{array}$

4.2.3.1 Informações gerais sobre as Poliaminas $\quad 57$

4.2.3.2 Estruturas da poliaminas $\quad 57$

4.3 Complexos de Cobre $\quad 59$

4.3.1 Síntese dos compostos binários $\left[\mathrm{Cu}\left(\mathrm{H}_{2} \mathrm{O}\right)_{2}(\mathrm{En})\right] \mathrm{SO}_{4}(\mathrm{CuEn1:1)}$ e $\left[\mathrm{Cu}(\mathrm{En})_{2}\right] \mathrm{SO}_{4}$ (CuEn2:1) 59

4.3.2 Dados experimentais dos complexos binários CuEn1:1 e CuEn2:1 59

4.3.2.1 Informações gerais sobre os compostos $\quad 59$

4.3.2.2 Análise Elementar $\quad 59$

4.3.2.3 UV-Visível 60

4.3.2.4 Infravermelho 60

4.3.2.5 Estruturas propostas para os complexos binários 60

4.3.3 Síntese do composto binário $\left[\mathrm{Cu}\left(\mathrm{H}_{2} \mathrm{O}\right)(\mathrm{PCr})\right](\mathrm{CuPCr})$

4.3.4 Dados experimentais do complexo $\left[\mathrm{Cu}\left(\mathrm{H}_{2} \mathrm{O}\right)(\mathrm{PCr})\right] \quad 61$

4.3.4.1 Informações gerais sobre o composto 61 
4.3.5 Tentativa de síntese dos compostos ternários $[C u(P A)(P C r)]$

4.3.6 Dados experimentais do complexo obtido na tentativa de síntese do composto ternário $\mathrm{CuTnPCr}$

4.3.6.1 Informações gerais sobre o composto

4.3.7 Síntese dos compostos ternários $[\mathrm{Cu}(\mathrm{PA})(\mathrm{ATP})] \cdot \mathrm{H}_{2} \mathrm{O} . \mathrm{nHCl} \quad 62$

4.3.8 Dados experimentais dos complexos ternários $[\mathrm{Cu}(\mathrm{PA})(\mathrm{ATP})] \cdot \mathrm{H}_{2} \mathrm{O} . \mathrm{nHCl}$

4.3.8.1 Informações gerais sobre os compostos 63

4.3.9 Síntese dos compostos binários tetraclorocupratos $\left[\mathrm{CuCl}_{4}\right][\mathrm{PA}] \quad 63$

4.3.10 Dados experimentais dos complexos tetraclorocupratos 64

4.3.10.1 Informações gerais sobre os compostos 64

4.4 Complexos de Cobalto

64

4.4.1 Síntese dos compostos binários tetraclorocobaltato $\left[\mathrm{CoCl}_{4}\right][\mathrm{PA}] \quad 64$

4.4.2 Dados experimentais dos complexos tetraclorocobaltato 65

4.4.2.1 Informações gerais sobre os compostos 65

4.5 Complexos de Cádmio

4.5.1 Síntese dos compostos binários tetraclorocadmato $\left[\mathrm{CdCl}_{4}\right][\mathrm{PA}] \quad 65$

4.5.2 Dados experimentais dos complexos tetraclorocadmato

66

4.5.2.1 Informações gerais sobre os compostos 66

5 Resultados e Discussão

67

5.1 Complexos de cobre

68

5.1.1 Complexos de cobre com fosfocreatina 68

5.1.1.1 Geral 68

5.1.1.2 Análise Termogravimétrica 70

5.1.1.3 Infravermelho - Análise visual dos espectros 72

5.1.1.4 Ressonância Paramagnética de Elétron 76

5.1.1.5 Cálculo Teórico 77

5.1.2 Complexos tenários de cobre com ATP e as poliaminas 84

5.1.2.1 Geral 84

5.1.2.2 Análise Termogravimétrica 86

5.1.2.3 Infravermelho 91

5.1.2.4 Ressonância paramagnética de elétron $\quad 95$

5.1.3 Complexos binários de cobre com as poliaminas 96

5.1.3.1 Geral 96

5.1.3.2 Análise termogravimétrica dos complexos tetraclorocupratos $\quad 97$

$\begin{array}{lll}\text { 5.1.3.3 Infravermelho } & 101\end{array}$

5.1.3.4 Ultravioleta-Visível 104

5.1.3.5 Difração de Raio-X 105

$\begin{array}{lll}5.2 & \text { Complexos de cobalto } & 108\end{array}$

5.2.1 Complexos binários de cobalto com as poliaminas 108

5.2.1.1 Geral 108

5.2.1.2 Análise termogravimétrica dos complexos tetraclorocobaltato 109

$\begin{array}{ll}\text { 5.2.1.3 Infravermelho } & 112\end{array}$

5.2.1.4 Ultravioleta-Visível 115

5.2.1.5 Difração de raio X 116

$\begin{array}{lll}5.3 \text { Complexos de cádmio } & 117\end{array}$ 
5.3.1 Complexos binários de cádmio com as poliaminas 117

5.3.1.1 Geral 117

5.3.1.2 Análise termogravimétrica dos complexos de cádmio 118

5.3.1.3 Infravermelho 121

5.3.1.4 UV dos complexos de cádmio 123

5.3.1.5 Ressonância Magnética Nuclear 125

5.3.1.6 Difração de Raio X 130

6 Conclusões $\quad 131$

6.1 Complexos de cobre 131

6.1.1 Complexo binário de cobre com fosfocreatina 131

6.1.2 Complexos ternários de cobre com ATP e as poliaminas 132

6.1.3 Complexos binários de cobre com as poliaminas 134

$\begin{array}{lll}6.2 & \text { Complexos de cobalto } & 135\end{array}$

6.2.1 Complexos de binários de cobalto com as poliaminas 135

6.3 Complexos de cádmio 136

6.3.1 Complexos de binários de cádmio com as poliaminas 136

$\begin{array}{lll}6.4 & \text { Considerações finais } & 137\end{array}$

$\begin{array}{lr}\text { Referências Bibliográficas } & 138\end{array}$

$\begin{array}{ll}\text { A Apêndice } & 147\end{array}$

$\begin{array}{lll}\text { A.1 Lista de Abreviaturas } & 147\end{array}$

$\begin{array}{ll}\text { A.2 Análise Termogravimétrica } & 148\end{array}$

$\begin{array}{lll}\text { A.2.1 Ligantes } & 148\end{array}$

A.2.2 Complexos de Cobre(II) 153

A.2.3 Complexos de Cobalto(II) 153

A.2.4 Complexos de Cádmio(II) 162

A.3 Infravermelho 165

$\begin{array}{ll}\text { A.3.1 Ligantes } & 165\end{array}$

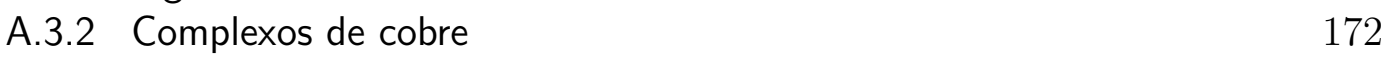

$\begin{array}{lll}\text { A.3.3 Complexos de Cobalto (II) } & 188\end{array}$

A.3.4 Complexos de cádmio (II) 193

$\begin{array}{lll}\text { A.4 UV-Visível } & 198\end{array}$

$\begin{array}{ll}\text { A.4.1 Ligantes } & 198\end{array}$

$\begin{array}{ll}\text { A.4.2 Complexos de cobre (II) } & 201\end{array}$

A.4.3 Complexos de cobalto (II) 205

A.4.4 Complexos de cádmio (II) 207

A.5 RMN de ${ }^{1} \mathrm{H}$ e ${ }^{13} \mathrm{C} \quad 210$

$\begin{array}{lll}\text { A.5.1 Ligantes } & 210\end{array}$

A.5.2 Complexos de cádmio 214

A.6 RMN de ${ }^{113} C d \quad 218$ 


\section{Lista de figuras}

$\begin{array}{lll}2.1 & \text { Estrutura das poliaminas naturais } & 19\end{array}$

2.2 Biossíntese das poliaminas 21

2.3 Catabolismo das poliaminas naturais 23

2.4 Putrescina em ligação de hidrogênio 24

2.5 Modelo de interação entre a Spd e o AMP em pH biológico 26

2.6 Interação das poliaminas com RNA 27

2.7 Complexos das aminas protonadas 30

2.8 Estrutura de um ligante poliazamacrociclo com ânions tetracloropaladato (II) 32

2.9 Porção da estrutura cristalina de um ligante poliazamacrociclo com ânions hexacianocobaltato (III) 33

2.10 ATP 34

2.11 Estruturas propostas para complexos com ATP e alguns íons metálicos divalentes $\quad 35$

$\begin{array}{ll}2.12 \text { Síntese da Fosfocreatina } & 38\end{array}$

3.1 Interação do íon $\mathrm{Mg}^{2+}$ com o difosfato 42

3.2 Proposta para mecanismo de hidrólise do ATP 43

3.3 Estrutura da Vitamina $B_{1} 2$ em que $\mathrm{R}=C N^{-} \quad 47$

$\begin{array}{lll}4.1 & \text { Estrutura do ATP } & 56\end{array}$

4.2 Estrutura da PCr 56

4.3 Estrutura da Etilenodiamina 57

4.4 Estrutura do 1,3-diaminopropano 57

4.5 Estrutura da Putrescina $\quad 57$

4.6 Estrutura da Espermidina 58

4.7 Estrutura da Espermina 58

4.8 Estrutura do composto $\left[\mathrm{Cu}\left(\mathrm{H}_{2} \mathrm{O}\right)_{2}(\mathrm{En})\right] \mathrm{SO}_{4}$

4.9 Estrutura do composto $\left[\mathrm{Cu}(\mathrm{En})_{2}\right] \mathrm{SO}_{4} \quad 60$

5.1 Estrutura da Fosfocreatina 68

5.2 Curva TGA dos complexos de cobre(II) com PCr (CuPCr -esquerda e CuTnPCr - direita) 72

5.3 Espectros IV dos compostos de fosfocreatina com cobre(II)

5.4 Estrutura do composto $\left[\mathrm{Cu}\left(\mathrm{H}_{2} \mathrm{O}\right)(\mathrm{PCr})\right] \quad 78$

5.5 Geometrias distorcidas de alguns modos normais: $598(-)$ esquerda e 491 (-)direita 83

5.6 Geometrias distorcidas de alguns modos normais: 480 (474) esquerda e 440 (458)direita 84

5.7 Geometrias distorcidas de alguns modos normais: 408 (397) esquerda e 311 (301)direita 84

5.8 Estrutura do composto $[C u(E n)(A T P)]$

5.9 Estrutura do composto $[C u(T n)(A T P)]$

5.10 Estrutura do composto $[C u(S p d)(A T P)] \quad 94$

5.11 Estrutura do composto $[C u(\operatorname{Spm})(A T P)]$ 
5.12 Fotos dos complexos CuSpd (esquerda) na forma de pó e CuSpm (direita) na forma de cristal

5.13 Estrutura do composto $\left[\mathrm{CuCl}_{4}\right][\mathrm{En}]$

5.14 Estrutura do composto $\left[\mathrm{CuCl}_{4}\right][\mathrm{Tn}] \quad 100$

5.15 Estrutura do composto $\left[\mathrm{CuCl}_{4}\right][\mathrm{Put}] \quad 101$

5.16 Estrutura do composto $\left[\mathrm{CuCl}_{4}\right][\mathrm{Spd}] \quad 101$

5.17 Estrutura do composto $\left[\mathrm{CuCl}_{4}\right][\mathrm{Spm}] \quad 101$

5.18 Rede cristalina do complexo $\left[\mathrm{CuCl}_{4}\right][\mathrm{Spm}]$ mostrando as espécies $\left[\mathrm{CuCl}_{4}\right]$ com uma coordenação do tipo $4+2 \quad 102$

5.19 Espectros do ligante Spd e do complexo Cuspd 103

5.20 Espectro UV-Visível do complexo de cobre(II) com putrescina e do sal $\mathrm{CuCl}_{2}$ em água. ( $\mathrm{CuCl}_{2}$-esquerda e CuPut - direita) 105

5.21 Estrutura molecular do complexo CuSpm 107

5.22 Vista do complexo CuSpm segundo o eixo cristalográfico "b" 107

5.23 Vista do complexo CuSpm segundo o eixo cristalográfico "a" 108

5.24 Fotos dos complexos CoTn na forma de pó e na forma de cristal 109

5.25 Estrutura do composto $\left[\mathrm{CoCl}_{4}\right][\mathrm{En}]$

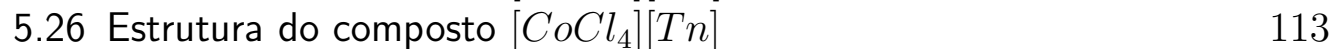

5.27 Estrutura do composto $\left[\mathrm{Co}\left(\mathrm{Cl}_{2}\right)\left(\mathrm{H}_{2} \mathrm{O}\right)_{4}\right][\mathrm{Put} .2 \mathrm{HCl}]$

5.28 Estrutura do composto $\left[\mathrm{CoCl}_{4}\right][\mathrm{Spd.HCl}]$

5.29 Estrutura do composto $\left[\mathrm{CoCl}_{4}\right][\mathrm{Spm} .2 \mathrm{HCl}]$

5.30 Espectros do ligante Put e do complexo CoPut 114

5.31 Espectro UV-Visível do complexo de cobalto(II) com 1,3diaminopropano e do sal $\mathrm{CoCl}_{2}$ em água. $\left(\mathrm{CoCl}_{2}\right.$ - esquerda e CoTn direita)

5.32 Estrutura Cristalina do complexo CoPut

5.33 Fotos dos complexos CdTn (esquerda) e CdSpm (direita), ambos na forma de cristal

5.34 Estrutura do composto $\left[\mathrm{CdCl}_{4}\right][\mathrm{En}] \quad 124$

5.35 Estrutura do composto $\left[\mathrm{CdCl}_{4}\right][\mathrm{Tn}]$

5.36 Estrutura do composto $\left[\mathrm{CdCl}_{4}\right][\mathrm{Put}] \quad 125$

5.37 Estrutura do composto $\left[\mathrm{CdCl}_{4}\right][\mathrm{Spd}] \quad 125$

5.38 Estrutura do composto $\left[\mathrm{CdCl}_{4}\right][\mathrm{Spm}] \quad 125$

5.39 Estrutura Cristalina do complexo $\left[\mathrm{CdCl}_{4}\right][\mathrm{Spm} .2 \mathrm{HCl}]$

$\begin{array}{lll}\text { A.1 TGA da fosfocreatina } & 149\end{array}$

A.2 TGA do ATP 149

A.3 TGA da etilenodiamina.2 $\mathrm{HCl}$

A.4 TGA do 1,3-diaminopropano.2HCl $\quad 150$

$\begin{array}{ll}\text { A.5 TGA da putrescina.2HCl } & 151\end{array}$

$\begin{array}{lll}\text { A.6 TGA da espermdina.3HCl } & 151\end{array}$

A.7 TGA da espermina.4HCl 152

A.8 TGA do complexo $\mathrm{CuPCr} r$

A.9 TGA do complexo CuTnPCr 153

A.10 TGA do complexo CuEnATP 154

A.11 TGA do complexo CuTnATP 154

A.12 TGA do complexo CuSpdATP 155

A.13 TGA do complexo CuSpmATP $\quad 155$

A.14 TGA do complexo CuEn 156 
A.15 TGA do complexo CuTn $\quad 156$

A.16 TGA do complexo CuPut 157

A.17 TGA do complexo CuSpd 157

A.18 TGA do complexo CuSpm 158

A.19 TGA do complexo CuEn 1:1 158

A.20 TGA do complexo CuEn 2:1 159

A.21 TGA do complexo CoEn 159

A.22 TGA do complexo CoTn 160

A.23 TGA do complexo CoPut 160

A.24 TGA do complexo CoSpd 161

A.25 TGA do complexo CoSpm 161

A.26 TGA do complexo CdEn 162

A.27 TGA do complexo CdTn 162

A.28 TGA do complexo CdPut 163

A.29 TGA do complexo CdSpd 163

A.30 TGA do complexo CdSpm 164

A.31 IV do ligante $\operatorname{PCr}\left(4000-450 \mathrm{~cm}^{-1}\right) \quad 165$

A.32 IV do ligante PCr $\left(700-30 \mathrm{~cm}^{-1}\right) \quad 165$

A.33 IV do ligante ATP $\left(4000-450 \mathrm{~cm}^{-1}\right) \quad 166$

A.34 IV do ligante ATP $\left(700-30 \mathrm{~cm}^{-1}\right) \quad 166$

A.35 IV do ligante En.2HCl $\left(4000-450 \mathrm{~cm}^{-1}\right) \quad 167$

A.36 IV do ligante En.2HCl $\left(700-30 \mathrm{~cm}^{-1}\right) \quad 167$

A.37 IV do ligante $\mathrm{Tn} .2 \mathrm{HCl}\left(4000-450 \mathrm{~cm}^{-1}\right) \quad 168$

A.38 IV do ligante $\mathrm{Tn} .2 \mathrm{HCl}\left(700-30 \mathrm{~cm}^{-1}\right) \quad 168$

A.39 IV do ligante Put.2HCl $\left(4000-450 \mathrm{~cm}^{-1}\right) \quad 169$

A.40 IV do ligante Put.2HCl $\left(700-30 \mathrm{~cm}^{-1}\right) \quad 169$

A.41 IV do ligante Spd.3HCl $\left(4000-450 \mathrm{~cm}^{-1}\right) \quad 170$

A.42 IV do ligante Spd.3HCl $\left(700-30 \mathrm{~cm}^{-1}\right) \quad 170$

A.43 IV do ligante Spm.4HCI $\left(4000-450 \mathrm{~cm}^{-1}\right) \quad 171$

A.44 IV do ligante Spm.4HCl $\left(700-30 \mathrm{~cm}^{-1}\right) \quad 171$

A.45 IV do Complexo CuEn1:1 (4000 - $\left.450 \mathrm{~cm}^{-1}\right)$

A.46 IV do Complexo CuEn1:1 (700-30 $\left.\mathrm{cm}^{-1}\right) \quad 173$

A.47 IV do Complexo CuEn2:1 (4000 - $\left.450 \mathrm{~cm}^{-1}\right) \quad 173$

A.48 IV do Complexo CuEn2:1 $\left(700-30 \mathrm{~cm}^{-1}\right) \quad 174$

A.49 IV do Complexo CuPCr (4000-450 $\left.\mathrm{cm}^{-1}\right)$

A.50 IV do Complexo CuPCr $\left(700-30 \mathrm{~cm}^{-1}\right) \quad 175$

A.51 IV do Complexo CuTnPCr (4000-450 $\left.\mathrm{cm}^{-1}\right) \quad 175$

A.52 IV do Complexo CuTnPCr $\left(700-30 \mathrm{~cm}^{-1}\right) \quad 176$

A.53 IV do Complexo CuEnATP (4000 - $\left.450 \mathrm{~cm}^{-1}\right)$

A.54 IV do Complexo CuEnATP $\left(700-30 \mathrm{~cm}^{-1}\right) \quad 177$

A.55 Ampliação do IV do Complexo CuEnATP $\left(700-30 \mathrm{~cm}^{-1}\right) \quad 177$

A.56 IV do Complexo CuTnATP $\left(4000-450 \mathrm{~cm}^{-1}\right) \quad 178$

A.57 IV do Complexo CuTnATP $\left(700-30 \mathrm{~cm}^{-1}\right) \quad 178$

A.58 Ampliação do IV do Complexo CuTnATP $\left(700-30 \mathrm{~cm}^{-1}\right) \quad 179$

A.59 IV do Complexo CuSpdATP (4000 - $\left.450 \mathrm{~cm}^{-1}\right) \quad 179$

A.60 IV do Complexo CuSpdATP $\left(700-30 \mathrm{~cm}^{-1}\right) \quad 180$

A.61 Ampliação do IV do Complexo CuSpdATP $\left(700-30 \mathrm{~cm}^{-1}\right) \quad 180$

A.62 IV do Complexo CuSpmATP $\left(4000-450 \mathrm{~cm}^{-1}\right) \quad 181$ 
A.63 IV do Complexo CuSpmATP $\left(700-30 \mathrm{~cm}^{-1}\right) \quad 181$

A.64 Ampliação do IV do Complexo CuSpmATP $\left(700-30 \mathrm{~cm}^{-1}\right) \quad 182$

A.65 IV do Complexo CuEn (4000 - $\left.450 \mathrm{~cm}^{-1}\right)$

A.66 IV do Complexo CuEn $\left(700-30 \mathrm{~cm}^{-1}\right) \quad 183$

A.67 IV do Complexo CuTn $\left(4000-450 \mathrm{~cm}^{-1}\right) \quad 183$

A.68 IV do Complexo CuTn $\left(700-30 \mathrm{~cm}^{-1}\right) \quad 184$

A.69 IV do Complexo CuPut $\left(4000-450 \mathrm{~cm}^{-1}\right) \quad 184$

A.70 IV do Complexo CuPut $\left(700-30 \mathrm{~cm}^{-1}\right)$

A.71 IV do Complexo CuSpd (4000-450 $\left.\mathrm{cm}^{-1}\right) \quad 185$

A.72 IV do Complexo CuSpd $\left(700-30 \mathrm{~cm}^{-1}\right) \quad 186$

A.73 IV do Complexo CuSpm (4000-450 $\left.\mathrm{cm}^{-1}\right) \quad 186$

A.74 IV do Complexo CuSpm $\left(700-30 \mathrm{~cm}^{-1}\right) \quad 187$

A.75 IV do Complexo CoEn $\left(4000-450 \mathrm{~cm}^{-1}\right) \quad 188$

A.76 IV do Complexo CoEn $\left(700-30 \mathrm{~cm}^{-1}\right) \quad 188$

A.77 IV do Complexo CoTn $\left(4000-450 \mathrm{~cm}^{-1}\right) \quad 189$

A.78 IV do Complexo CoTn $\left(700-30 \mathrm{~cm}^{-1}\right) \quad 189$

A.79 IV do Complexo CoPut $\left(4000-450 \mathrm{~cm}^{-1}\right) \quad 190$

A.80 IV do Complexo CoPut $\left(700-30 \mathrm{~cm}^{-1}\right) \quad 190$

A.81 IV do Complexo CoSpd $\left(4000-450 \mathrm{~cm}^{-1}\right) \quad 191$

A.82 IV do Complexo CoSpd $\left(700-30 \mathrm{~cm}^{-1}\right) \quad 191$

A.83 IV do Complexo CoSpm (4000-450 $\left.\mathrm{cm}^{-1}\right) \quad 192$

A.84 IV do Complexo CoSpm $\left(700-30 \mathrm{~cm}^{-1}\right) \quad 192$

A.85 IV do Complexo CdEn $\left(4000-450 \mathrm{~cm}^{-1}\right) \quad 193$

A.86 IV do Complexo CdEn $\left(700-30 \mathrm{~cm}^{-1}\right) \quad 193$

A.87 IV do Complexo CdTn $\left(4000-450 \mathrm{~cm}^{-1}\right) \quad 194$

A.88 IV do Complexo CdTn $\left(700-30 \mathrm{~cm}^{-1}\right) \quad 194$

A.89 IV do Complexo CdPut $\left(4000-450 \mathrm{~cm}^{-1}\right) \quad 195$

A.90 IV do Complexo CdPut $\left(700-30 \mathrm{~cm}^{-1}\right)$

A.91 IV do Complexo CdSpd (4000-450 $\left.\mathrm{cm}^{-1}\right)$

A.92 IV do Complexo CdSpd $\left(700-30 \mathrm{~cm}^{-1}\right) \quad 196$

A.93 IV do Complexo CdSpm (4000-450 $\left.\mathrm{cm}^{-1}\right) \quad 197$

A.94 IV do Complexo CdSpm $\left(700-30 \mathrm{~cm}^{-1}\right) \quad 197$

A.95 UV do ligante En 198

A.96 UV do ligante Tn 198

A.97 UV do ligante Put $\quad 199$

$\begin{array}{ll}\text { A.98 UV do ligante Spd } & 199\end{array}$

A.99 UV do ligante Spm 200

A.100UV-Visível do complexo CuEn1:1 201

A.101UV-Visível do complexo CuEn2:1 201

A.102UV-Visível do sal $\mathrm{CuCl}_{2} \quad 202$

A.103UV-Visível do complexo CuEn 202

A.104UV-Visível do complexo CuTn 203

A.105UV-Visível do complexo CuPut 203

A.106UV-Visível do complexo CuSpd 204

A.107UV-Visível do complexo CuSpm 204

A.108UV do sal $\mathrm{CoCl}_{2} \quad 205$

A.109UV-Visível do complexo CoEn 205

A.110UV-Visível do complexo CoTn 205 
A.111UV-Visível do complexo CoPut 206

A.112UV-Visível do complexo CoSpd 206

A.113UV-Visível do complexo CoSpm 206

A.114UV do sal $C d C l_{2} \quad 207$

A.115UV do Complexo CdEn 207

A.116UV do Complexo CdTn 208

A.117UV do Complexo CdPut 208

A.118UV do Complexo CdSpd 209

A.119UV do Complexo CdSpm 209

A.120RMN de ${ }^{1} H$ da En 210

A.121RMN de ${ }^{13} \mathrm{C}$ da En $\quad 210$

A.122RMN de ${ }^{1} H$ da Tn 211

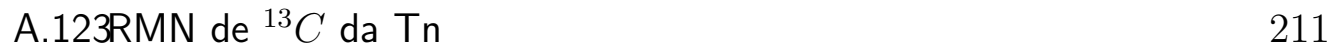

A.124RMN de ${ }^{1} H$ da Put $\quad 211$

A.125RMN de ${ }^{13} \mathrm{C}$ da Put $\quad 212$

A.126RMN de ${ }^{1} H$ da Spd $\quad 212$

A.127RMN de ${ }^{13} \mathrm{C}$ da Spd $\quad 213$

A.128RMN de ${ }^{1} H$ da Spm 213

A.129RMN de ${ }^{13} C$ da Spm 213

A.130RMN de ${ }^{1} H$ do CdEn 214

A.131RMN de ${ }^{13} \mathrm{C}$ do $\mathrm{CdEn} \quad 214$

A.132RMN de ${ }^{1} H$ do $\mathrm{CdTn} \quad 215$

A.133RMN de ${ }^{13} \mathrm{C}$ do $\mathrm{CdTn} \quad 215$

A.134RMN de ${ }^{1} H$ do CdPut $\quad 215$

A.135RMN de ${ }^{13} C$ do CdPut $\quad 216$

A.136RMN de ${ }^{1} H$ do CdSpd 216

A.137RMN de ${ }^{13} \mathrm{C}$ do CdSpd 216

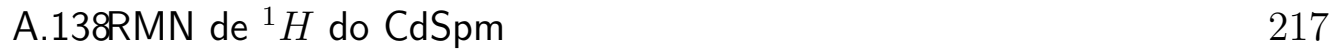

A.139RMN do Sal $\mathrm{CdCl}_{2} \quad 218$

A.140RMN do Complexo CdEn 218

A.141RMN do Complexo CdTn 218

A.142RMN do Complexo CdSpd 218

A.143RMN do Complexo CdSpm 219 
Portanto, procurai com zêlo os melhores dons; $e$ eu vos mostrarei um caminho ainda mais excelente.

Coríntios, 12; 31. 